\title{
Glass transition temperature of nanoparticle-enhanced and environmentally stressed conductive adhesive materials for electronics assembly
}

\author{
Pavel Mach ${ }^{1} \cdot$ Attila Geczy $^{1,2} \cdot$ Radek Polanský $^{3} \cdot$ David Bušek $^{1}$ \\ Received: 17 October 2018 / Accepted: 3 January 2019 / Published online: 12 February 2019 \\ (C) The Author(s) 2019
}

\begin{abstract}
In our paper, the characterization of glass transition temperature ( $\mathrm{Tg}$ ) was performed for one- and two-component electrically conductive adhesive used in electronic joining technologies. Both adhesives were of the epoxy type with the silver filler. Dynamic mechanical analysis (DMA) was used to measure the Tg. The adhesives were modified with nanoparticles, namely, carbon nanotubes (concentration of 0.5 and $0.8 \%$ by weight) and silver nanoballs ( $2.5 \%$ by weight). The values of $\mathrm{Tg}$ were determined from the plot of the $\mathrm{Tg} \delta$ parameter. Two types of environmental stresses were used for climatic aging: $125^{\circ} \mathrm{C} / 56 \% \mathrm{RH}$ and $85{ }^{\circ} \mathrm{C} / 85 \% \mathrm{RH}$. The aging of the samples at $125^{\circ} \mathrm{C}$ and $56 \% \mathrm{RH}$ caused increase $\mathrm{Tg}$ for all formulations. The cause of these changes is additional curing of adhesive. Aging in the combined climate $85^{\circ} \mathrm{C} / 85 \% \mathrm{RH}$ caused a shift in $\mathrm{Tg}$ toward lower values for formulations based on the one-component adhesive modified by CNT and toward higher values for all other formulations. The major cause of the decrease in Tg was that CNT inhered the curing reactions and banned them from completion. In cases where Tg grew, glue hardening take place. DMA was performed to examine $\mathrm{Tg}$ of the samples. The DMA measurements were carried out up to $200{ }^{\circ} \mathrm{C}$. Repeated DMA measurement confirmed that this measurement caused additional hardening and increase $\mathrm{Tg}$ for all samples. The results will contribute to the use of conductive adhesives with better quality and reliability in electronics manufacturing.
\end{abstract}

\section{Introduction}

Conductive adhesives have significant advantages over conventional solders, however, in given cases. Adhesive joints are more flexible and creep resistant, and the curing temperature of ECAs is lower than the soldering temperatures. Adhesives with isotropic electrical conductivity (ICAs) are often used for surface mounting components sensitive to heat, die attachment and small passive chip attachment.

Pavel Mach

mach@fel.cvut.cz

$\triangle$ Attila Geczy

gattila@ett.bme.hu

1 Department of Electrotechnology, Czech Technical University in Prague, Technická 1902/2, Praha, Czech Republic

2 Department of Electronics Technology, Budapest University of Technology and Economics, Egry J. u. 18., 1111 Budapest, Hungary

3 Department of Technologies and Measurement, University of West Bohemia, Univerzitní 8, Plzeň, Czech Republic
Adhesives with anisotropic electrical conductivity (ACAs) are used for interconnections in LCD displays, flexible electronics [1], surface mount technology of chip-scale packages, flip-chip and ball grid array technology. Using ACAs foils (ACFs) for mounting fine-pitch and ultrafine-pitch packages is more advantageous than soldering because there is no danger of creating short formations between adjacent terminations [2]. The detailed classification of adhesives used in assembling electronic circuits is carried out in [3].

Electrical conductivity of ECAs is inferior to lead-free solders [4]. Therefore, different ways of improving the conductivity of adhesives were tested. Hongjin et al. [5], Li et al. [1, 6] and Tan et al. [2] described different methods of functionalization of filler particles to improve the electrical conductivity of ICAs. Particle surface functionalization with an effective surfactant can result in more favorable low-temperature sintering and a significant reduction in the contact resistance between particles of the filler.

Properties of ICAs were also inspected for different structural variations. They were filled with microsized particles, mostly silver flakes; filled with microsized particles and modified by the addition of different types of nanosized 
particles in different concentrations; and filled by nanosized particles only. Examination of ICAs filled with $65 \mathrm{wt} \%$ silver microparticles modified by silver nanoparticles up to a concentration of $10 \mathrm{wt} \%$ showed that the resistivity of modified formulations increased in almost all cases [7]. Carbon nanotubes (CNT) are also often used for the modification of conductive adhesives with micro-fillers. The results presented in [8] showed that modification of a microadhesive with CNT caused an increase in the conductivity and adhesion strength of ICAs. The reason is probably the formation of physico-chemical bonds between the nanoparticles and epoxy resin. Marcq et al. examined adhesives with silver microfiller modified by CNT in concentrations of 0.4 vol. $\%$ and $1 \mathrm{vol} . \%$. They found that CNT increased the electrical conductivity as well as the glassy and rubbery moduli of the adhesive [9].

ICAs filled by nanoparticles only were inspected in [10]. Silver plating nanographite was used as a conductive filler and epoxy resin as an insulating matrix. However, the electrical conductivity achieved was lower than that achieved with silver microparticle-filled adhesives. The same conclusion was made in [11], where the authors also examined adhesive based on epoxy resin filled with CNT.

Regarding the thermomechanical properties of conductive adhesives, the examination of glassy and rubbery moduli of hybrid ICAs formed of epoxy resin filled with silver flakes and modified with CNT was mentioned in [9]. Li et al. inspected the loss moduli of cured ICAs without and with carboxylic acid in [1]. Masahiro and Liu measured the storage modulus and $\tan \delta$ of heat-resistant conductive adhesives [12]. Ren et al. examined the glass transition temperature in solar photovoltaic module interconnect assemblies [13], and $\mathrm{Li}$ and Wong measured this parameter for reworkable epoxy resin for isotropically conductive adhesives [14].

The glass transition temperature ( $\mathrm{Tg})$ is one of the most significant thermomechanical parameters of adhesives. This parameter may limit the use of conductive adhesives in some applications. However, thus far, a study focusing on changes in this parameter of electrically conductive adhesives caused by climatic aging has not been published. The same can be said about a study of the glass transition temperature of ICAs modified by the addition of conductive nanoparticles and changes of this temperature caused by climatic aging of these formulations. In the present work, the glass transition temperature of one-component and two-component conductive adhesives with epoxy matrix and silver filler as-received and after modifications with silver nanoballs and CNT were studied. The study was carried out for formulations without climatic aging, after aging at high temperature and in combination with high temperature/high relative humidity.

With respect to the wide spectrum of conductive adhesive applications, the properties of these materials must be studied to a greater extent. This will result in more optimized use and fewer failures during production and their lifetime. The results will extend the knowledge on the limitations, quality and reliability aspects of the materials in electronics assemblies.

\section{Materials and methods}

\subsection{Glass transition temperature of thermoset adhesives and its measurement}

Cured thermoset adhesives will not reflow or melt when heated, but they undergo a transition from rigid to rubbery state. This change occurs over a certain temperature interval. The midpoint of this interval is the glass transition temperature $\operatorname{Tg}$ [15-17]. At this interval mobility of the polymer chains increases fast. The material becomes soft and the cohesive failures become more probable. Especially in the cases, when a dynamic mechanical stress is applied on an adhesive joint. When the temperature of the adhesive rises over $\mathrm{Tg}$, the storage modulus, tensile strength and lap shear strength drop. The coefficient of thermal expansion increases by a multiple $3-5$. The thermal expansion of the adhesive above the temperature $\mathrm{Tg}$ may cause deterioration of contacts between filler particles and increase in the volume resistivity of adhesive. Also thermally induced stress of bonded components increases.

The $\mathrm{Tg}$ is significantly affected by a curing profile of the ahesive. The glass transition temperature of conductive adhesives is not based on the glass transition temperature of the resin that forms the binder of ICAs only but on the adhesion between the resin and the filler particles or particles that are used for modifying the adhesive.

The glass transition temperature is mostly measured using differential scanning calorimetry (DSC) and dynamic mechanical analysis (DMA). According to Foreman et al., DSC is the most common thermal analysis method used to measure $\mathrm{Tg}$ [18]. This parameter can also be measured using thermomechanical analysis (TMA), but the sensitivity of this method for measuring $\mathrm{Tg}$ is lower than the sensitivity of DSC and DMA [19]. In our paper, Tg was determined using DMA. There are more approaches to the DMA measurement. A three-point bending of a brick-shaped sample and a penetration mode method were tested for the measurement. The three-point bending was omitted for the reasons described later.

When the temperature of the glass transition is measured with DMA, the trace of the storage modulus, loss modulus or $\tan$ delta $(\tan \delta)$ can be used for the determination of this temperature [20]. In this paper, the presented values of the glass transition temperature were determined from the plot of $\tan \delta$. 


\subsection{Adhesives used for experiments}

There are many different ICA formulations used in electronics packaging. The combination epoxy binder-silver filler is used the most often.

Epoxy resin is a highly promising material. The properties of composites based on epoxy resins are constantly improved. Nanocomposites with an epoxy matrix, excellent mechanical properties and the increased glass transition temperature compared with that of pure epoxy are presented in [21], nanocomposites having a self healing effect are described in $[22,23]$. Nanocomposites are also used for EMC interference shielding [24].

As for filler, very interesting experiments are carried out with GE (graphene) and GNPs (graphene nanoplatelets) [25-27]. Graphene is technically a non-metal but is often referred to as a quasi-metal due to its properties being like that of a semi-conducting metal. These composite applications have excellent mechanical as well as electrical properties. At present, however, these adhesives are under development and we did not find them on the market.

Silver is a metal with the best electrical conductivity. A silver oxide is a conductor. Therefore adhesive based on the epoxy matrix filled with silver flakes were chosen for experiments.

Single-component type AX20 adhesive and two-component type AX15S adhesive (AMEPOX, Poland) were used for experiments. They both had an insulating matrix of bisphenol epoxy resin (blended formulation) filled with silver flakes. These materials are considered to be widely used in industry, so their improvement might give overall increased quality and reliability. It is also important to emphasize that the chosen types represent the one- and two-component type resins. The basic parameters of these adhesives are presented in Table 1.

The measurements were performed on the adhesives "asreceived" and on prepared samples, into which were mixed at a concentration of $0.5 \%$ by weight and $0.8 \%$ by weight, respectively. In our case, the CNTare multiwall carbon nanotubes with an average wall thickness of 3-19 graphene layers and bundle diameter of $44-800 \mathrm{~nm}$ (produced by chemical vapor deposition, Cat. No. 694185, Sigma-Aldrich, USA). The second type of prepared sample was formed of adhesives "as-received" and modified with silver nanoballs mixed at a concentration of $2.5 \%$ by weight (silver nanoballs with 99\% trace metals basis with diameter of the particles below 150 nm, Cat. No. 484059, Sigma-Aldrich, USA).

As for our case, nanoparticles were added to the adhesives by rotary agitation. A mechanical stirring tool was used for mixing. It was necessary to ensure the appropriate viscosity of the adhesive during this process. Curing of adhesives was carried out in accordance with the manufacturer's recommendations in a forced air circulation furnace under normal climatic conditions.

The designation of adhesives "as-received" and after different modifications are shown in Table 2.

\subsection{Test samples}

Our initial experiments involved brick-shaped samples. A mold of silicone rubber was manufactured, and the adhesives were applied into the mold in which the curing process was carried out. With the process, scantlings (with a thickness of $1.5 \mathrm{~mm}$, length of $15 \mathrm{~mm}$ and width of $5 \mathrm{~mm}$ ) were produced. It was found that solvent vaporization from the adhesives during the curing process caused the formation of many voids in the volume of the material. Therefore, curing of the adhesives in a vacuum at a pressure of $4 \mathrm{~Pa}$ was tested to improve this situation [28]. The manufactured samples in both cases, however, contained a considerable number of voids, and therefore, they were not suitable for basic DMA measurements. Therefore, a penetration mode for the DMA measurements was used, which is described below.
Table 1 Electrically conductive adhesives used for experiments

\begin{tabular}{lll}
\hline Type of adhesive & AX20 & AX15S \\
\hline Number of components & 1 & 2 \\
Percentage of silver (by weight) & $751 \%$ & $60 \pm 1 \%$ \\
Specific gravity $\left(\mathrm{g} / \mathrm{cm}^{3}\right)$ & $3.5-3.7$ & $1.6-2.6^{*}$ \\
Curing schedule in a forced air circulated oven $\left({ }^{\circ} \mathrm{C} /\right.$ & $150 /(5-10)$ & $20 / 24 \mathrm{~h}$ \\
min) & $180 /(3-8)$ & $150 / 15$ \\
Electrical resistivity $(\Omega \mathrm{m})$ & $(3.0-3.5) \mathrm{E}-6$ & $(10-12) \mathrm{E}-6^{* *}$ \\
& & $(1.7-1.8) \mathrm{E}-6^{* * *}$ \\
Curing schedule with air-circulated oven & $150{ }^{\circ} \mathrm{C}-(5-10) \mathrm{min}$ & $120^{\circ} \mathrm{C}-30 \mathrm{~min}$ \\
& $180{ }^{\circ} \mathrm{C}-(3-8) \mathrm{min}$ & $150{ }^{\circ} \mathrm{C}-15 \mathrm{~min}$ \\
\hline
\end{tabular}

\footnotetext{
*In dependence on viscosity

$* *$ For curing at $20^{\circ} \mathrm{C} / \mathrm{min}$

***FFor curing at $150{ }^{\circ} \mathrm{C} / \mathrm{min}$
} 
Table 2 Designations of formulations

\begin{tabular}{|c|c|c|c|}
\hline \multirow[t]{2}{*}{ Adhesive } & \multicolumn{3}{|l|}{ Added nanoparticles } \\
\hline & $2.5 \% \mathrm{nAg} *$ & $0.5 \% \mathrm{CNT}^{*}$ & $0.8 \% \mathrm{CNT}^{*}$ \\
\hline \multicolumn{4}{|c|}{ As-received } \\
\hline AX20 & $\mathrm{Ax} 20+2.5 \mathrm{nAg}$ & $\mathrm{AX} 20+0.5 \mathrm{CNT}$ & $\mathrm{AX} 20+0.8 \mathrm{CNT}$ \\
\hline AX15S & $\mathrm{AX} 15 \mathrm{~S}+2.5 \mathrm{nAg}$ & $\mathrm{AX} 15 \mathrm{~S}+0.5 \mathrm{CNT}$ & $\mathrm{AX} 15 \mathrm{~S}+0.8 \mathrm{CNT}$ \\
\hline \multicolumn{4}{|c|}{ After treatment at the temperature of $125^{\circ} \mathrm{C}$ for $300 \mathrm{~h}$} \\
\hline AX20 & Ax20+2.5nAg: $\mathrm{T}$ & AX20+0.5CNT: T & AX20+0.8CNT: T \\
\hline AX15S & $\mathrm{AX} 15 \mathrm{~S}+2.5 \mathrm{nAg}: \mathrm{T}$ & AX15S + 0.5CNT: T & AX15S + 0.8CNT: T \\
\hline \multicolumn{4}{|c|}{ After treatment at combined climate $85^{\circ} \mathrm{C} / 80 \% \mathrm{RH}$ for $300 \mathrm{~h}$} \\
\hline AX20 & $\mathrm{Ax} 20+2.5 \mathrm{nAg}: \mathrm{TH}$ & $\mathrm{AX} 20+0.5 \mathrm{CNT}: \mathrm{TH}$ & $\mathrm{AX} 20+0.8 \mathrm{CNT}: \mathrm{TH}$ \\
\hline AX15S & $\mathrm{AX} 15 \mathrm{~S}+2.5 \mathrm{nAg}: \mathrm{TH}$ & AX15S+0.5CNT: TH & AX15S+0.8CNT: TH \\
\hline
\end{tabular}

*Weight percent

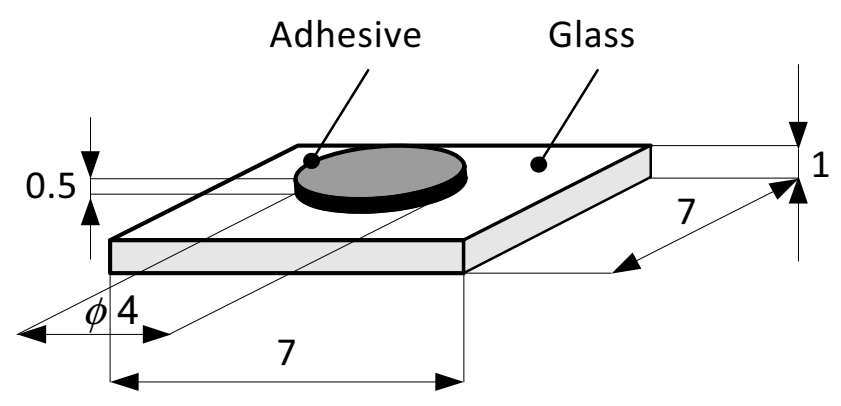

Fig. 1 Specimen for measurement. Dimensions are in $\mathrm{mm}$

For sample holding purposes, glass plates were used that had a $1 \mathrm{~mm}$ thickness, $26 \mathrm{~mm}$ width and $76 \mathrm{~mm}$ length.

The adhesives were applied on the glass substrates by stencil printing. A stencil of silicon rubber was prepared by punching a 0.5 -mm-thick silicon foil with 4-mm-diameter apertures. Curing of the adhesives was carried out directly in the stencil, which was removed after curing. Finally, the test samples were formed by segmenting the substrate with deposited samples into squares of $7 \times 7 \mathrm{~mm}$.

The sample setup is presented in Fig. 1.

\subsection{Climatic treatment}

The climatic treatment was performed in two different types of environments. One part of the samples was aged at $125^{\circ} \mathrm{C}$ and $56 \% \mathrm{RH}$, and the second part was aged at $85^{\circ} \mathrm{C}$ and $85 \%$ RH (JESD22-A118). The aging at $125^{\circ} \mathrm{C}$ was carried out in an air-circulated oven under normal laboratory conditions; the, aging at high relative humidity was carried out in a temperature and humidity test chamber (Clima Temperatur Systeme $+10 / 200$ ). The aging time was $300 \mathrm{~h}$ in all cases.

\subsection{DMA measurements}

Dynamic mechanical analysis was employed to determine $\mathrm{Tg}$ values. A TMA Q400EM device from TA Instruments was used for these measurements. This device is primarily intended for thermomechanical analysis (TMA), but the dynamic mode for dynamic mechanical analysis (D-TMA) is also available. In this mode, a sinusoidal force and linear temperature ramp are applied on the specimen. Of the measured values from the resulting sinusoidal strain and sine wave phase differences, the storage modulus $E^{\prime}$, loss modulus $E^{\prime \prime}$ and $\tan \delta$ were calculated as a function of the temperature, time or stress [29].

The measurements were carried out using a penetration probe. The device was flushed with dry air $(100 \mathrm{ml} /$ min) during the measurement. The sample was subjected to repeated heating from the ambient temperature to $200{ }^{\circ} \mathrm{C}$ during analysis. The applied compressive force was $0.30 \mathrm{~N}$, and the modulating force was $+/-0.20 \mathrm{~N}$ with a frequency of $1 \mathrm{~Hz}$.

The glass transition temperature was determined from the $\tan \delta$ measurement. Due to the use of the temperature range from ambient temperature to $200{ }^{\circ} \mathrm{C}$ for the $\tan \delta$ measurement, the samples were additionally cured during this measurement. To find how this additional hardening the glass transition temperature values, the $\tan \delta$ plots were measured once more. The results of these measurements are marked as in the figures below.

\section{Results and discussion}

The measured $\tan \delta$ curves for adhesive AX20 are shown in Figs. 2 and 3. The results presented in Fig. 2 were obtained from the first measurement. Measurement 2 results are shown in Fig. 3.

The measurements provided several interesting points for discussion. Initial measurements performed on "as-received" 
Fig. 2 Values of $\tan \delta$ for adhesive AX20 and modifications of this adhesive before and after climatic treatment. The results were obtained during Meas. 1
Fig. 3 Values of $\tan \delta$ for adhesive AX20 and modifications of this adhesive before and after climatic treatment. The results were obtained during Meas. 2
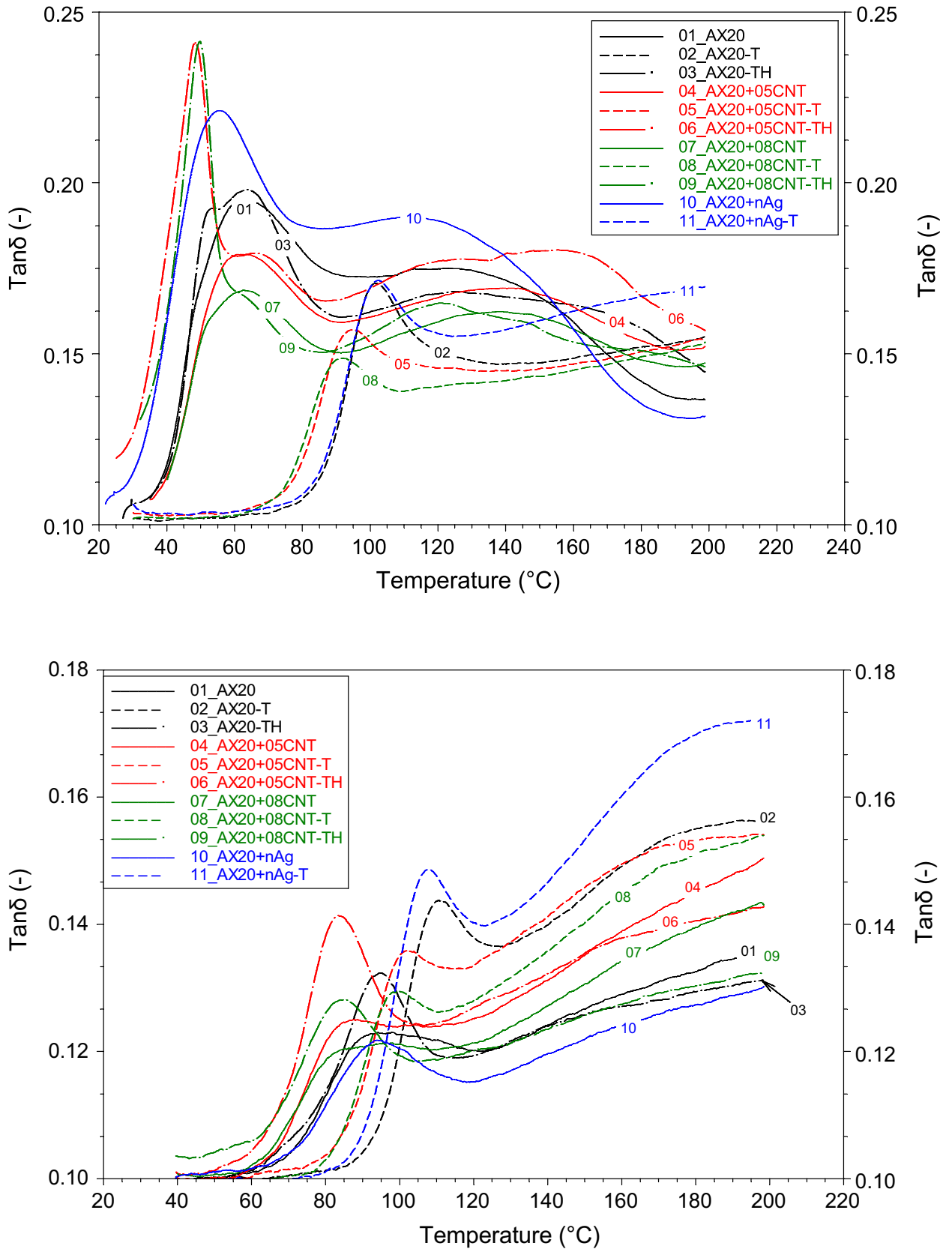

adhesive AX20 (Figs. 2, 4, Meas. 1) yielded a Tg of $62.4{ }^{\circ} \mathrm{C}$. The addition of CNT at concentrations of $0.5 \%$ and $0.8 \%$ resulted in only very low changes of $\mathrm{Tg}$ in either of the cases (Fig. 4), whereas the addition of silver nanoballs at a concentration of $2.5 \%$ by weight caused a decrease of this temperature by approximately $11.5 \%$ on the value of $55.2{ }^{\circ} \mathrm{C}$. The percentage changes of $\mathrm{Tg}$ caused by modification of adhesive AX20 by CNT and silver nanoballs are shown in Fig. 5 . All changes are related to Tg of adhesive "as-received" in this figure.

The coefficient of thermal expansion (CTE) of silver is $1.9 \mathrm{E}-5 \mathrm{~K}^{-1}$, and the CTE of bisphenol epoxy resin is substantially higher at $7.0 \mathrm{E}-5 \mathrm{~K}^{-1}$ (or more dependent on the type and manner of processing of the resin). Filling of the epoxy matrix with silver flakes that forms a conductive net in the adhesive causes a decrease of the CTE of the adhesive in comparison with the CTE of the matrix itself [30]. When the adhesive is heated, the differences between the CTE of the matrix and filler cause internal stress, which influences the thermodynamic mechanical properties and causes a change of Tg. It is surprising that the addition of $\mathrm{nAg}$ at such a low concentration caused such a significant change in the $\mathrm{Tg}$. However, if these nanoparticles are dispersed between the filler particles, and the arrangement of the filler particles in the adhesive changes, then this change can result in a higher change in the $\mathrm{Tg}$ value of the composite. 


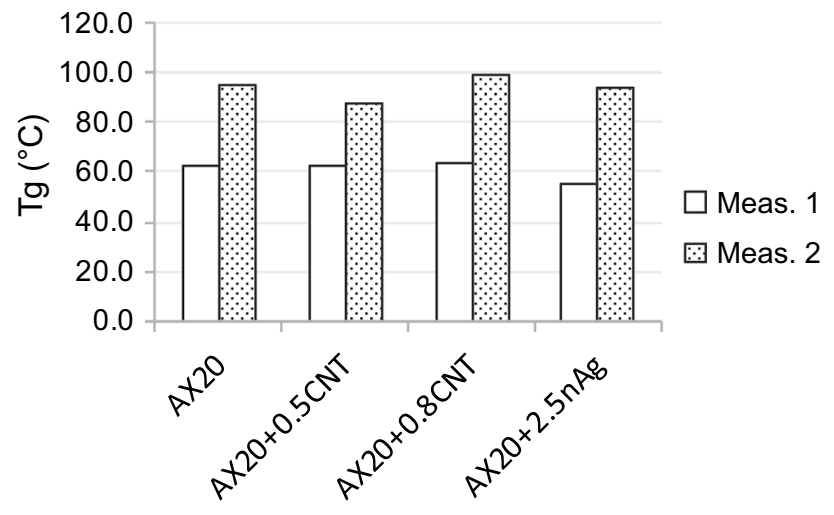

Formulation

Fig. 4 Tg of adhesive AX20 and its modifications

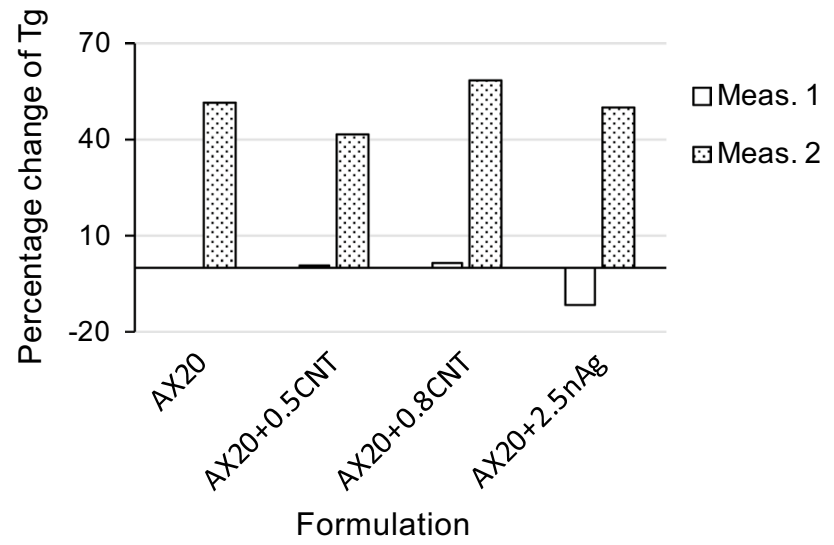

Fig. 5 Percentage changes of Tg of adhesive AX20 after modification by CNT in concentration of 0.5 and/or $0.8 \%$ by weight respectively and by silver nanoballs in concentration of $2.5 \%$ by weight after the first measurement (Meas. 1) and second measurement (Meas. 2) of $\tan \delta$. All changes are related to Tg of adhesive "as-received"

Another possible mechanism that can significantly contribute to the decrease in Tg after modification of the adhesive by silver nanoparticles is the change of free volumes between the polymer chains. When the nanoparticles increase the free volumes, e.g. by pushing the chains apart, the movability of the chains increases and the Tg drops. Another possibility is that the added nanoparticles influence the curing reactions in the adhesive and prevent cross-linking of the polymer chains. The axial CTE of carbon nanotubes was studied by Shirasu et al. [31]. Wei et al. studied the CTE of nanotube polymer composites [32]. For the composition of an epoxy resin modified with the addition of $0.5 \%$ and $0.8 \%$ by volume multiwalled CNT, the CTE value was approximately $6.0 \mathrm{E}-5 \mathrm{~K}^{-1}$. The value of the CTE is very close to the value of the CTE of the epoxy resin. Under the assumption that a strong interaction exists between the
CNT and neighboring polymer chains, the CNT would influence the motions of the molecules in their surroundings and increase the $\mathrm{Tg}$ of the formulation.

This assumption was partially confirmed by our measurements, as shown in Figs. 4 and 5. There was a low increase in the Tg value found for modifications with CNT.

The additional curing induced by the first $\tan \delta$ measurement caused an increase in the glass transition temperature for all the formulations (Figs. 3, 4, Meas. 2). When the measured values were compared with the value of $\tan \delta$ of adhesive AX20 "as-received" and recalculated to relative changes, the increase in the value of $\tan \delta$ was as follows: $52 \%$ for the formulation "as-received", $41 \%$ for modification AX20+0.5CNT, 58\% for modification AX20+0.8CNT and $50 \%$ for modification AX20 $+2.5 \mathrm{nAg}$. This means that all formulations were additionally hardened by the first measurement of $\tan \delta$.

The Tg of all formulations after the thermal stress at $125{ }^{\circ} \mathrm{C}$ under laboratory conditions $(56 \% \mathrm{RH})$ for $300 \mathrm{~h}$ is presented in Fig. 6 (Meas. 1). If the measured values of $\mathrm{Tg}$ are compared with the previous values presented in Fig. 4 (Meas. 1), it is clear that there was an increase of $\mathrm{Tg}$ in all formulations caused by hardening of adhesive by the thermal stress. The percentage increase of the Tg after this type of climatic aging was significant. For adhesive "as-received", it was 64\%; for adhesive modified by CNT at concentrations of 0.5 and $0.8 \%$, by weight it was $51 \%$ and $44 \%$, respectively; and for adhesive modified by silver nanoballs, it was 86\% (see Fig. 8, thermal treatment of each formulation). The changes are related to the values of the $\mathrm{Tg}$ for adhesive "as-received" and its modifications in Fig. 4. The reason for this increase is the hardening of the resin due to thermal loading, which is always associated with an increase of the glass transition temperature if the loading is not too intense or if it does not last so long that the resin starts to degrade.

The difference in the $\mathrm{Tg}$ between modifications by silver nanoballs and CNT could be caused by the different CTE

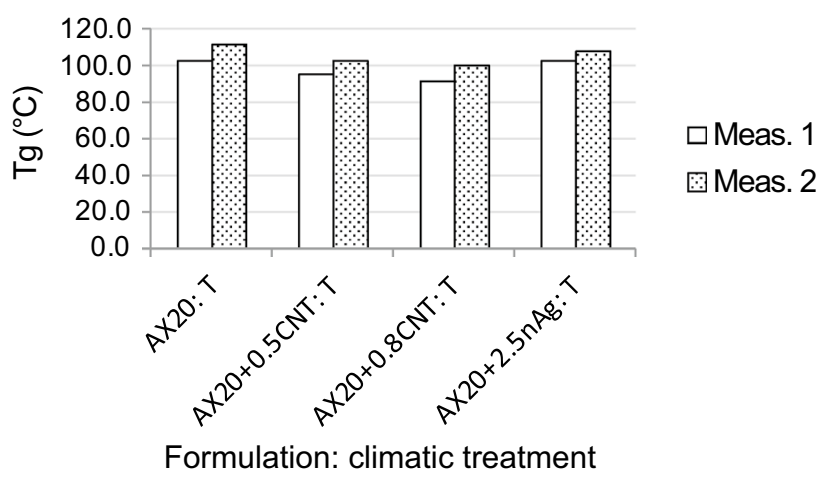

Fig. $6 \mathrm{Tg}$ values of adhesive AX20 as-received and for its modifications after thermal treatment $\left(125^{\circ} \mathrm{C}, 300 \mathrm{~h}\right)$ 
for silver nanoparticles and CNT, respectively. The value of $\mathrm{Tg}$ is also increased after the second measurement with the $\tan \delta$ (Meas. 2), although less than in the case of non-aged formulations presented in Fig. 4. The reason is that climatic aging at the high temperature was performed before the first measurement of $\tan \delta$. This aging caused additional curing of the formulations. Therefore, the changes in $\mathrm{Tg}$ after the additional curing induced by the first $\tan \delta$ measurement were smaller than that of the "as-received" adhesive.

The adsorption of moisture in a polymer matrix of ICAs can lead to a wide spectrum of changes in the adhesive properties. Some are reversible and disappear after the water is removed from the adhesive. Some are irreversible and permanently change the properties of the adhesive. Ivanova et al. [32] found that the introduction of water into a polymeric material causes swelling that changes the mechanical properties of the material. Liu et al. [32] examined the properties of conductive adhesives after exposure to hot/wet environments. They found that such exposure could cause structuring damage by inducing microcavities that can further accelerate moisture diffusion. In addition, oxidation effects can occur in the material after a certain exposure time. Bowdich [33] and Kasturiarachchi et al. [34] showed that the absorbed water could attack the matrix/filler interface and cause debonding at the interface. Saarinen et al. [35] confirmed this finding. They found that the adhesion deteriorates due to moisture accumulated on the surface and chemical changes in the adhesive caused by adsorbed water in the matrix. The chemical changes may cause oxidation and hydrolysis of the polymer because new hydroxyl and carbonyl end groups that reduce the average molecular weight can be formed. The cross-link density and adhesion strength may decrease as well. All of the abovementioned processes can influence the glass transition temperature.

In Fig. 7, Tg values for all formulations aged under combined climatic conditions $\left(85^{\circ} \mathrm{C} / 85 \% \mathrm{RH}\right.$ for $\left.300 \mathrm{~h}\right)$ are presented. Figure 8 presents the percentage changes $\mathrm{Tg}$

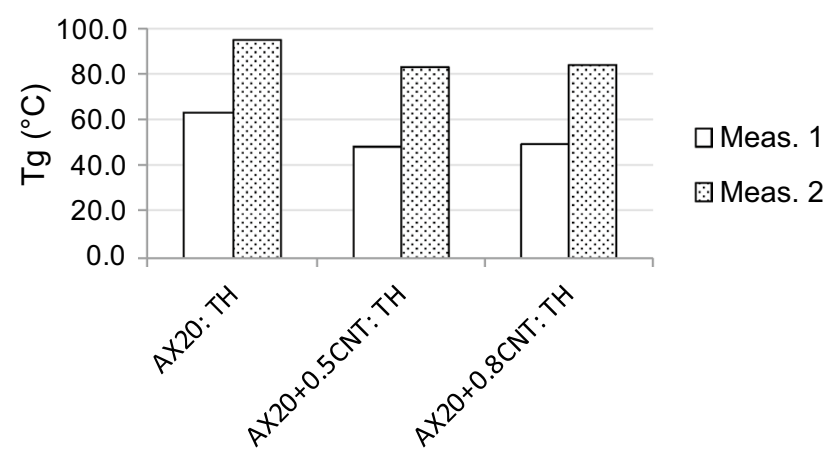

Formulation: climatic treatment

Fig. $7 \mathrm{Tg}$ values of adhesive AX20 as-received and for its modifications after combined climatic treatment $\left(85^{\circ} \mathrm{C} / 85 \% \mathrm{RH}, 300 \mathrm{~h}\right)$

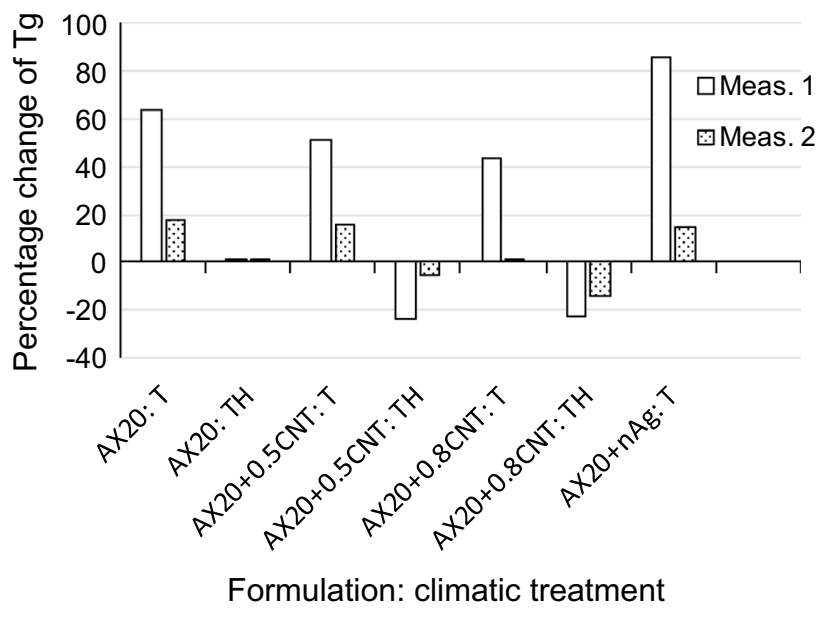

Fig. 8 Percentage change Tg of adhesive AX20 and its modifications after both types of climatic treatment related to $\mathrm{Tg}$ of every formulation before climatic treatment (values shown in Figs. 6, 7 are compared with values presented in Fig. 4). Changes were reported after the first and second $\tan \delta$ measurements

caused by combined climatic aging related to Tg of adhesive AX20 and its modifications before climatic treatment. A comparison of the results presented in Figs. 4 and 7 shows that adhesive "as-received" did not change the value of $\mathrm{Tg}$ after this type of aging. On the other hand, for both formulations with CNT, the glass transition temperature was reduced by approx. $15 \%$. It should be noted that $\mathrm{Tg}$ for sample AX20+2.5nAg after treatment in the combined climate is lacking in Fig. 7. This is because during the exposure of the samples, the adhesive sample became separated from the substrate so that measurement of this sample under the same conditions as the others was not possible.

After the combined climatic treatment, a slight decrease in Tg for modifications with CNT was found (Figs. 7, 8, Meas. 1). Because the change of the "as-received" adhesive induced by this type of aging was negligible, th change must be due to the modification of this adhesive by the CNT.

There are two possible mechanisms according to our findings:

1. The carbon nanotubes act as a catalyst for the penetration of water into the epoxide. However, this is only possible if the CNT are sufficiently hydrophilic. The nanotubes can be in wide range of hydrophobicity and hydrophilicity. The CNT are inherently somewhat hydrophilic, with a water contact angle of less than $86^{\circ}$ [36]. It is possible, using a proper functionalization of the CNT surface, to increase the wettability. Oxygen, air, and different acids or acid mixtures [37] may make this process. The effects of plasma treatment on the surface wettability of carbon nanotube bucky papers and aligned nanotubes is presented in [20]. 
2. The carbon nanotubes influence the process of adhesive hardening or free volumes in adhesive. However, Fig. 4 shows that the values of Tg of adhesive "as received" and adhesive modified by CNT are the same. Therefore the mechanism 1 is more probable.

For the results obtained in the second measurement of tan $\delta$ (Figs. 7, 8, Meas. 2), there was no change in the level of $\mathrm{Tg}$ for the formulation "as-received". Adhesives modified by the CNT were slightly upgraded, which again shows a slight additional hardening of the adhesive.

The percentage changes between the $\mathrm{Tg}$ values found at measurement 1 (Meas. 1) and measurement 2 (Meas. 2) for all formulations based on adhesive AX20 and both types of

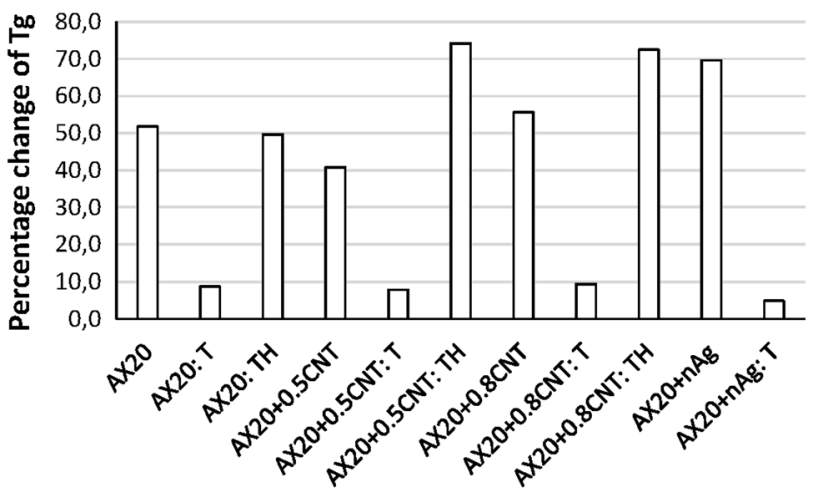

Formulation: climatic treatment

Fig. $9 \mathrm{Tg}$ percentage change of adhesive AX20 for adhesive asreceived and for individual modifications. Changes were calculated between the $\mathrm{Tg}$ value detected after the second measurement (Meas. 2) and after the first measurement (Meas. 1) of $\tan \delta$. climatic treatment are shown in Fig. 9. It was confirmed that the first measurement of $\tan \delta$ caused additional hardening of the adhesive, which was manifested by an increase in the glass transition temperature detected during the subsequent measurement. It was found that the addition of CNT in the concentrations used did not cause a significant change in the adhesive properties from this point of view. The addition of silver nanoparticles shows that the formulation was more sensitive to additional curing. The reason for the high increase of the $\mathrm{Tg}$ after modification of adhesive with $\mathrm{nAg}$ was discussed. Additional thermal curing can cause changes in the internal structure of the formulation and increase the Tg.

After thermal aging, the changes induced by the additional cure caused by the first $\tan \delta$ measurement (Meas. 1 ) were small. On the other hand, changes found after the exposure of the samples to the combined climate $\left(85^{\circ} \mathrm{C} / 85 \%\right.$ $\mathrm{RH})$ were very high for all formulations. The adhesive was first dried and then cured during the second measurement of $\tan \delta$.

The same measurements and the same evaluating procedures were used to study the two-component AX15S adhesive. The $\tan \delta$ values obtained at the first $\tan \delta$ measurement (Meas. 1) are shown in Fig. 10, and the values obtained at the second measurement (Meas. 2) are in Fig. 11.

The influence of the addition of CNT at concentrations of $0.5 \%$ and $0.8 \%$ by weight and silver nanoballs at concentrations of $2.5 \%$ by weight into adhesive AX15S on the value of $\mathrm{Tg}$ is shown in Fig. 12. The percentage change of this parameter related to the value of $\mathrm{Tg}$ of adhesive AX15S "as-received" is presented in Fig. 13. Addition of both types of nanoparticles into the adhesive
Fig. 10 Values of $\tan \delta$ for adhesive AX15S and modifications of this adhesive before and after climatic treatment. The results were obtained during the first measurement

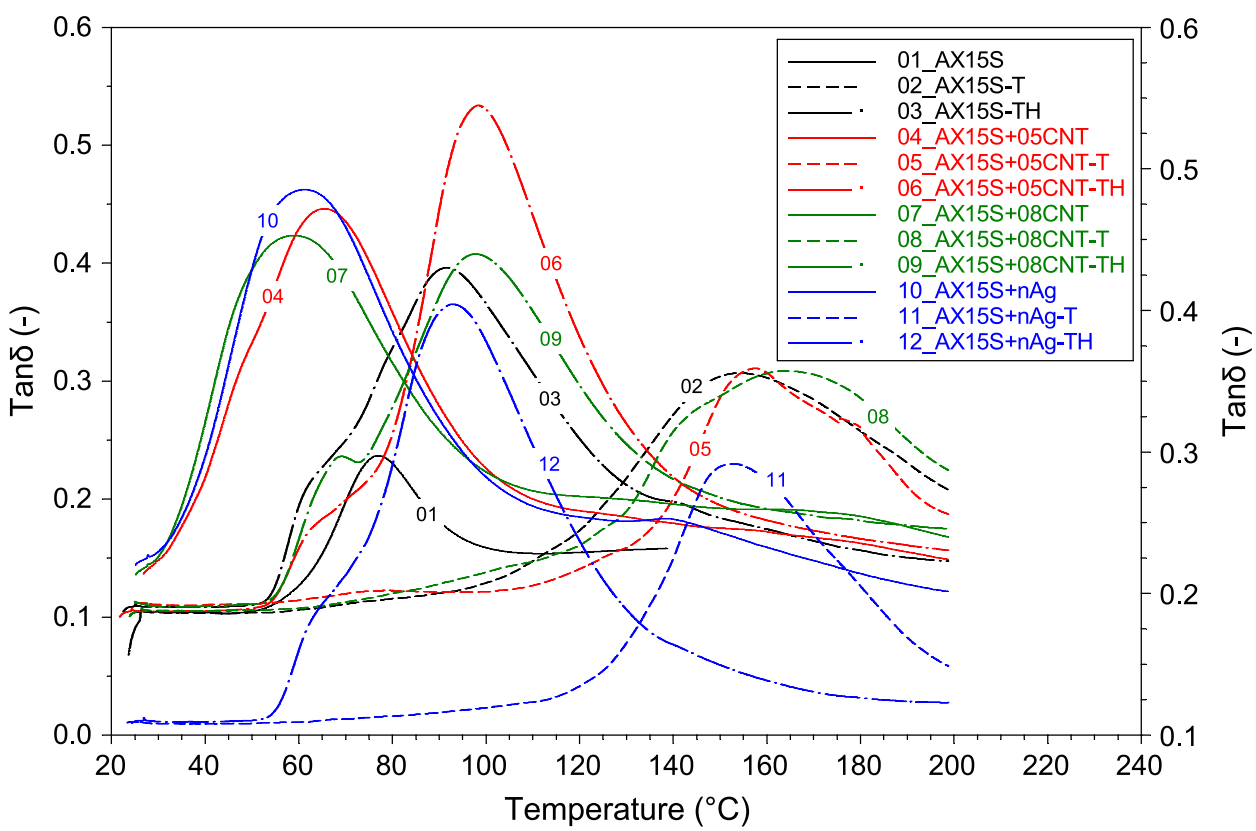


Fig. 11 Values of $\tan \delta$ for adhesive AX15S and modifications of this adhesive before and after climatic treatment. The results were obtained during Meas. 2

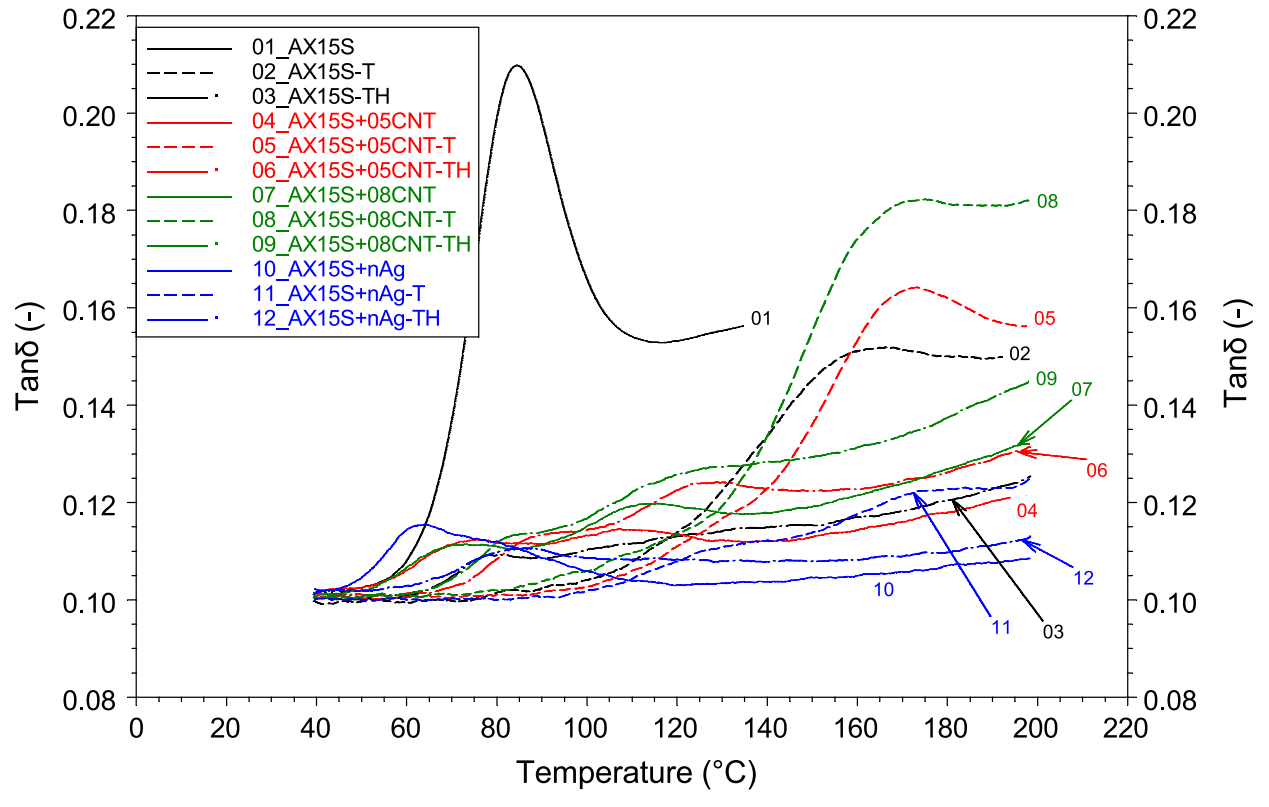

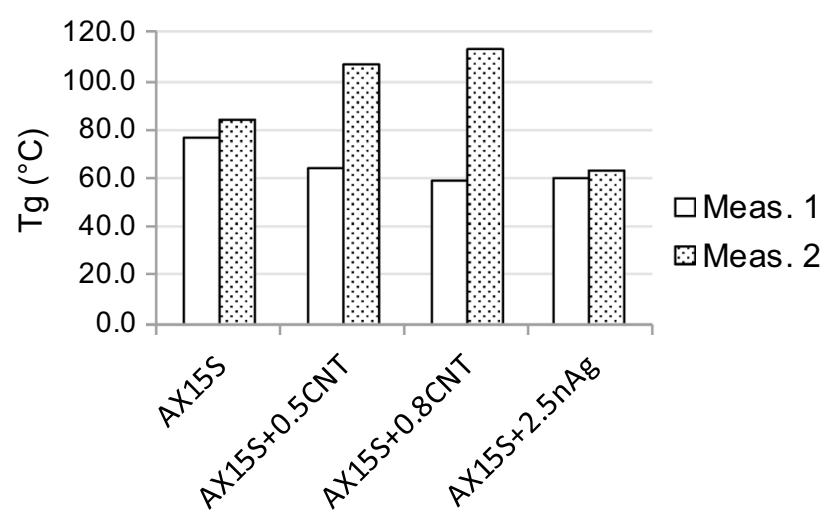

Formulation

Fig. $12 T g$ values of adhesive AX15S as-received and for its modifications

caused a decrease of $\mathrm{Tg}$ for all formulations in comparison with the adhesive "as-received". The decrease for the formulation AX15S $+0.5 \mathrm{CNT}$ was $16 \%$, for formulation AX15S + 0.8CNT it was $24 \%$ and for formulation $\mathrm{AX} 15+2.5 \mathrm{nAg}$ it was $22 \%$. There is a difference in comparison with the adhesive AX20, where the addition of CNT did not cause a reduction of the value of $\mathrm{Tg}$ and the addition of silver nanoballs caused a low decrease of this parameter only. Whereas the AX20 adhesive is a one-component type, AX15S is a two-component type resin. The reason may be that the nanoparticles interfered the curing reactions and banned them from completion. It can be clarified by investigating the E's at rubbery regions and that is why small $\mathrm{Tg}$ differences were found among samples 02, 05, 08 and 11.

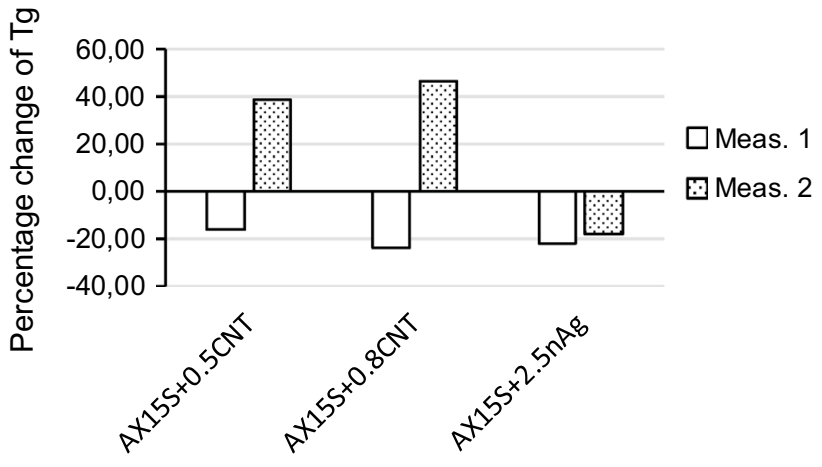

Formulation

Fig. 13 Percentage changes of Tg of adhesive AX15S after modification by CNT for concentrations of 0.5 and/or $0.8 \%$ by weight and by silver nanoballs for a concentration of $2.5 \%$ by weight after the first measurement (Meas. 1) and second measurement (Meas. 2) of $\tan \delta$. All changes are related to Tg of adhesive "as-received"

The high temperature was able to compensate for the lack of reactions.

As shown in Figs. 12 and 13, the values of Tg found for all formulations in the first measurement of $\tan \delta$ (Meas. 1) were lower than values of this parameter found in the second measurement (Meas. 2). The cause is the same as in the case of adhesive AX20, where the adhesive was additionally hardened by the first measurement of $\tan \delta$.

Figure 14 (Meas. 1) presents changes of $\mathrm{Tg}$ caused by thermal aging at $125{ }^{\circ} \mathrm{C}$ under laboratory conditions $(56 \%$ $\mathrm{RH})$ for $300 \mathrm{~h}$. This situation is the same as the change of $\mathrm{Tg}$ induced by thermal aging in the AX20 adhesive and its modifications; the increase of $\mathrm{Tg}$ was caused by additional hardening of adhesive with this type of environmental stress. 


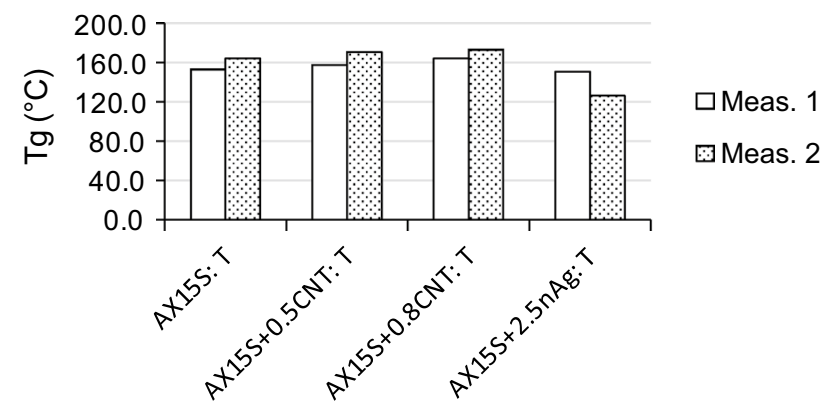

Formulation: climatic treatment

Fig. $14 \mathrm{Tg}$ values of adhesive AX15S and its modifications after thermal treatment $\left(125^{\circ} \mathrm{C}, 300 \mathrm{~h}\right)$

For adhesive "as-received", the increase was higher than $90 \%$. For formulation AX15S + 0.5CNT, the Tg increased by almost $150 \%$. For formulation AX15S $+0.8 \mathrm{CNT}$, the $\mathrm{Tg}$ increased by $180 \%$, and finally, for the formulation AX15S $+2.5 \mathrm{nAg}$, an increase of $150 \%$ was found (Fig. 16, thermal treatment of all formulations).

Repeated measurement of $\tan \delta$ confirmed an additional hardening of all formulations that resulted in higher values of $\mathrm{Tg}$ with the exception of the formulation of the AX15S adhesive with silver nanoballs. The reason was already presented in the discussion about the results in Figs. 12 and 13.

The results measured after the climatic aging of adhesive AX15S and its modifications in combined climate $85^{\circ} \mathrm{C} / 85 \%$ RH are presented in Fig. 15 (Meas. 1). This climatic stress caused an increase in Tg in every formulation in comparison with the values of this parameter for formulations without climatic aging. The increase was $19.1 \%$ for adhesive "asreceived", $52.0 \%$ for adhesive modified by $0.5 \%$ by weight CNT, $66.7 \%$ for adhesive modified by $0.8 \%$ by weight CNT and $55.0 \%$ for modification by $2.5 \%$ by weight $\mathrm{nAg}$ (Fig. 16 , $\mathrm{TH}$ treatment for all formulations). However, the value of the $\mathrm{Tg}$ found after the combined climatic aging of samples

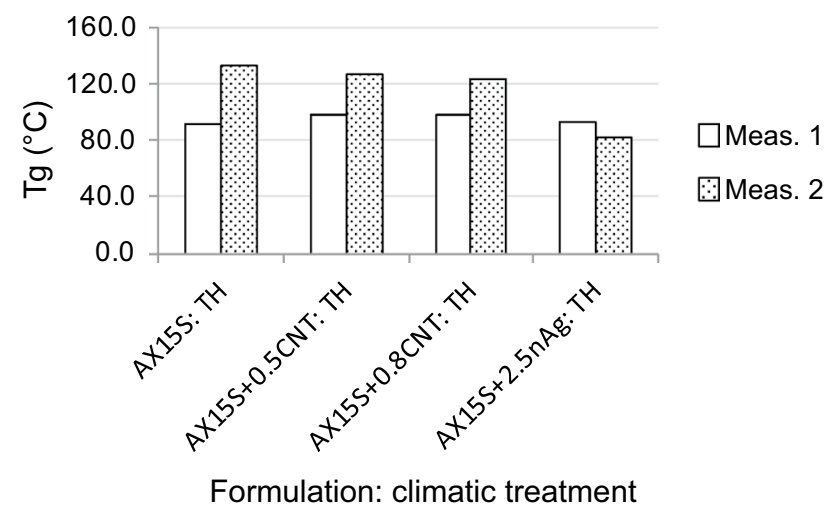

Fig. $15 \mathrm{Tg}$ values of adhesive AX15S and its modifications after combined climatic treatment $\left(85^{\circ} \mathrm{C} / 85 \% \mathrm{RH}, 300 \mathrm{~h}\right)$

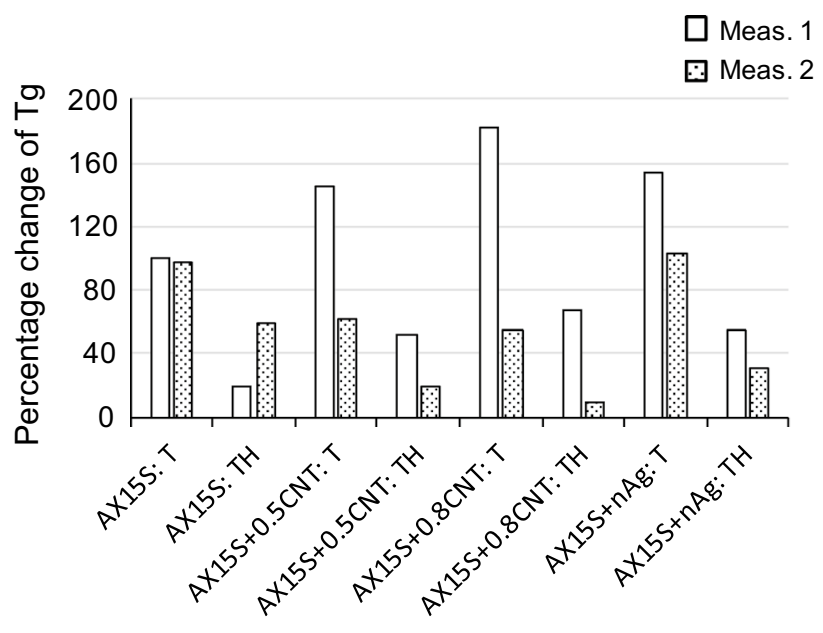

Formulation: climatic treatment

Fig. 16 Percentage change $T g$ of adhesive AX15S and its modifications related to $T g$ of every formulation before climatic treatment for both types of climatic treatment

based on the adhesive AX 20 modified by CNT decreased; for adhesive AX15S, this value increased.

The moisture sorption in epoxy resin based ACA was studied by Khoo and Liu [32] and Ren et al. [13]. Measuring changes in ICA using FTIR is problematic due to low signal/noise resolution. The reason is probably the high concentration of silver filler in ICAs [13]. Therefore the epoxy adhesive with anisotropic electrical conductivity, where the situation is similar with ICA, was measured [32].

The difference FTIR spectrum of non-aged and aged epoxy resin, that represents changes caused by climatic aging, was measured. The climatic aging was carried out at the temperature of $85^{\circ} \mathrm{C}$ and relative humidity $85 \%$ for $41 \mathrm{~h}$. It was found continuing curing of adhesive, new ester bonds caused by further curing of the resin and two new bands attributed to hydroxyl groups were found. The first hydroxyl band occurs because of continuing curing and the second one shows the type bonding of water to the epoxy resin. It means that this type of aging causes aditional curing of adhesive, when the nanoparticles do not limit the curing reactions, which was observed in the case of AX20 adhesive.

The percentage change in the Tg values of the AX15S adhesive and its modifications related to $\mathrm{Tg}$ of every formulation before climatic aging are shown in Fig. 16. A comparison of Figs. 8 and 16 shows that the increase in the glass transition temperature caused by thermal stress at $125{ }^{\circ} \mathrm{C}$ was much more pronounced in the two-component AX15S adhesive and its modifications than in the AX20 single-component adhesive and its modifications. The same can be stated about the stressing of these adhesives and their modifications in a combined climate of $85^{\circ} \mathrm{C} / 85 \% \mathrm{RH}$. In this case, the CNT-filled resins showed a decrease of $\mathrm{Tg}$ for 
the AX20 adhesive and an increase for the AX15S adhesive. Changes in Tg caused by climatic aging of adhesives vary considerably. While the modification of AX20 adhesive by CNT nanoparticles did not induce a Tg change (Figs. 4, 5), the AX15S adhesive showed a significant decrease in $\mathrm{Tg}$ (Figs. 12, 13). It is assumed that the CNT did not allow to complete some reactions joined with curing of adhesive here. The same can be said for modifications with silver nanoparticles for both types of adhesives. It is also possible that the nanoparticles changed free volumes in resin and thus reduced the $\mathrm{Tg}$.

The aging of adhesives at the temperature of $125^{\circ} \mathrm{C}$ and relative humidity $56 \%$ can be considered as post-curing. Changes, observed for formulations AX20 and AX15S show additional hardening of adhesives (Figs. 8, 16). Therefore the $\mathrm{Tg}$ increased in all cases. The significant increase in $\mathrm{Tg}$ of the adhesive AX15S indicates that the adhesive was not fully cured.

The aging of adhesives at $85{ }^{\circ} \mathrm{C}$ and $85 \%$ RH did not changed properties of AX20 adhesive "as received", increased $\mathrm{Tg}$ for formulation with silver nanoparticles and caused decrease in Tg for both modifications with CNT (Fig. 8). These two formulations seem to have again stopped curing reactions by CNT. As for the adhesive AX15S, this aging caused increase in Tg for all formulations (Fig. 16). This confirmed that curing of adhesives also takes place under these conditions [32]. In terms of the glass transition temperature, the adhesive AX15S was much more sensitive to the climatic load than the adhesive AX20.

The percentage changes between the second measurement of $\tan \delta$ (Meas. 2) and the first measurement of this parameter (Meas. 1) for all formulations based on adhesive AX15S and both types of climatic treatment are presented in Fig. 17.

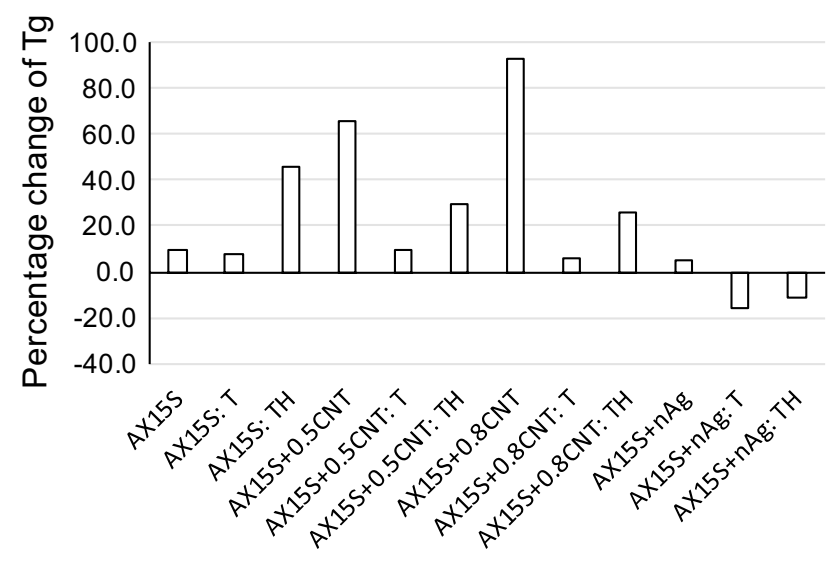

Formulation: climatic treatment

Fig. $17 \mathrm{Tg}$ percentage change of adhesive AX15S for adhesive asreceived and individual modifications. Changes were calculated between the $\mathrm{Tg}$ value detected after the second measurement (Meas. 2) and after the first measurement (Meas. 1) of $\tan \delta$.
It was confirmed that the first measurement of $\tan \delta$ caused additional hardening of the adhesive, which was manifested by a change in the glass transition temperature detected during the subsequent measurement. The value of Tg increased for all formulations except for the adhesive modified by $\mathrm{nAg}$ after thermal and combined climatic aging. The increase in temperature was caused by shrinkage of the adhesive and formation of additional cross-bonds [28] and increased the $\mathrm{Tg}$ value. The decrease of $\mathrm{Tg}$ for the formulation modified by silver nanoparticles was probably caused by the change of the internal structure of the adhesive after modification. Here, the additional curing during the first measurement weakened the matrix and filler adhesive bonds.

The maximum percentage change of $\mathrm{Tg}$ values caused by the first measurement of $\tan \delta$ was found for adhesives modified by CNT in both concentrations. The higher the concentration, the higher the change. The reason was explained by Wei et al. [31]. CNT have a strong interaction with neighboring molecules, influence the motions of these molecules and increase the $\mathrm{Tg}$ of the formulation.

The value of the glass transition temperature can significantly influence the application of a conductive adhesive. These materials are used in electronics for the adhesive assembly of electronic components, in power electrical engineering for manufacturing solar panels, and in many other applications. Exceeding the glass transition temperature changes the properties of adhesive bonds significantly. The change is particularly important in the area of mechanical properties of adhesive joints. In addition to changing other parameters, the tensile and shear strength of the adhesive decreases. Because electrically conductive joints must have not only good electrical but also good mechanical properties, this can affect the reliability of the adhesive joints, especially in combination with dynamic mechanical stress. The glass transition temperature can be exceeded in electrical equipment, for example, near power electronic components. Therefore, knowledge of the Tg values of conductive adhesives is very significant for achieving the required reliability of the adhesive assembly in electronic components.

\section{Conclusions}

It was found that modification of a one-component adhesive with CNT did not change the Tg, whereas the modification using $\mathrm{nAg}$ produced a small decrease in this temperature. For a two-component adhesive, modification with CNT and $\mathrm{nAg}$ reduced the $\mathrm{Tg}$ by approximately $20 \%$.

Environmental treatment at the high temperature and normal climatic conditions caused an increase in $\mathrm{Tg}$ for all formulations. In the two-component adhesive, the increase was approximately double that in the single-component adhesive. The increase of $\mathrm{Tg}$ was very high for individual formulations 
based on the one-component adhesive, where it was between 40 and $80 \%$ and for two-component adhesive between 70 and $180 \%$. The main reason for this increase was that the adhesives were not fully cured and by this type of ageing they were post-cured. In contrast to the treatment of test samples at the high temperature, the aging in combined climatic conditions caused a low decrease in the $\mathrm{Tg}$ of samples from the one-component adhesive modified by CNT, and no change in this temperature was observed for samples prepared from the adhesive "as-received". The samples based on the two-component adhesive showed an increase of $\mathrm{Tg}$ in the range from 20 to $65 \%$. The reasons for these changes were discussed. The major cause of these changes is the weakening of adhesive bonds by water molecules penetrating into the polymer matrix [33].

It was found that changes in the glass transition temperature caused by the thermal treatment and by treatment in the combined climate were much more pronounced for the twocomponent adhesive and its modifications than for the onecomponent adhesive. This means that the two-component adhesive was more susceptible to environmental stress than the one-component adhesive.

It was also found that the changes in $\mathrm{Tg}$ after environmental stress depended strongly on the type of stress. The percentage changes were considerably larger in the case when the load was done in a climate of high temperature and lower relative humidity than in the case when the load was done at higher relative humidity and a lower elevated temperature. Temperature played a dominant role in changes of $\mathrm{Tg}$ when the adhesive was environmentally aged.

The aging of the samples at the combined climatic conditions caused an increase in the value of Tg for all test samples formed from the two-component adhesive. For samples based on the one-component adhesive, the increase occurred for the formulation modified by nAg. The "as-received" formulation did not change, whereas the Tg decreased for both formulations with CNT. This effect can be connected to the assumption that the CNT facilitates penetration of water molecules into the adhesive, where the following chemical reactions decrease adhesion forces between the resin and filler particles [34]. A significant influence on the course of $\mathrm{Tg}$ during this type of ageing can also have the nanoparticles, especially when limit some chemical reactions courses or change free volumes in the resin.

The $\tan \delta$ measurement was carried out at a temperature range from ambient to the $200{ }^{\circ} \mathrm{C}$. This treatment also caused additional curing and shrinkage of the adhesive. Therefore, the measurement of $\tan \delta$ was repeated for every specimen. The change of Tg after the first $\tan \delta$ measurement was confirmed for all samples under test. Regarding the one-component adhesive, the $\mathrm{Tg}$ value increased for all formulations and for both types of climatic treatment. For the two-component adhesive, the $\mathrm{Tg}$ increased for adhesive "as-received", for modifications with CNT for both types of aging and for modification with silver balls without climatic treatment. The $\mathrm{Tg}$ of the adhesive modified by $\mathrm{nAg}$ decreased after both types of climatic treatment.

This study showed that a high range of values of the glass transition temperature for conductive adhesives can be achieved by modification of these materials with $\mathrm{nAg}$ and CNT. It also showed changes in the Tg caused by treatment of these materials at a high temperature and at combined climatic conditions. Knowledge of $\mathrm{Tg}$ contributes to better understanding on the topic, clearing the contrary question of whether nanoparticles enhance the quality or not, and improving assembly quality in manufacturing and reliable use of conductive adhesives.

Acknowledgments Open access funding provided by Budapest University of Technology and Economics (BME).

Data Availability The raw/processed data are available at the authors by request.

Open Access This article is distributed under the terms of the Creative Commons Attribution 4.0 International License (http://creativeco mmons.org/licenses/by/4.0/), which permits unrestricted use, distribution, and reproduction in any medium, provided you give appropriate credit to the original author(s) and the source, provide a link to the Creative Commons license, and indicate if changes were made.

\section{References}

1. Y. Li, K.-S. Moon, C.P. Wong, Electrical property improvement of electrically conductive adhesives through in-situ replacement by short-chain difunctional acids. IEEE Trans. Components Pack. Technol. 29(1), 173-178 (2006)

2. X. Fatang Tan, J. Qiao, H. Chen, Wang, Effects of coupling agents on the properties of epoxy-based electrically conductive adhesives. Int. J. Adhes. Adhes. 26, 406-413 (2006)

3. J.J. Licari, D.W. Swanson, Adhesives technology for electronic applications-materials, processing, reliability (Elsevier Inc., New York, 2011), pp. 1-34

4. Y.G. Li, D. Lu, C.P. Wong, Electrical conductive adhesives with nanotechnologies (Springer, Germany, 2010), pp. 176-178

5. H. Jiang, K.-S. Moon, J. Lu, C.P. Wong, Conductivity enhancement of nano silver-filled conductive adhesives by particle surface functionalization. J. Electron. Mater. 34(11), 1432-1439 (2005)

6. Y. Li, K.-S. Moon, H. Li, C.P. Wong, Conductivity improvement of isotropic conductive adhesives with short-chain dicarboxylic acids, in Proceedings of IEEE 54th electronic components and technology conference (ECTC), 2004, pp. 1959-1964

7. N. Xiong, M. Wang, H. Zhang, H. Xie, Y. Zhao, Y. Wang, J. $\mathrm{Li}$, Sintering behavior and effect of silver nanoparticles on the resistivity of electrically conductive adhesives composed of silver flakes. J. Adhes. Sci. Technol. 28(24), 2402-2415 (2014)

8. Q.H. Li., J.H. Zhang, Effects of nano fillers on the conductivity and reliability of isotropic conductive adhesives (ICAs). Key Eng. Mater. 2789, 353-358 (2007)

9. F. Marcq, P. Demont, P. Monfraix, A. Peigney, Ch Laurent, T. Falat, F. Courtade, T. Jamin, Carbon nanotubes and silver flakes 
filled epoxy resin for new hybrid conductive adhesives. Microelectron. Reliab. 51(7), 1230-1234 (2011)

10. L. Wei, X. Xi, C. Yu, Research of silver plating nano-graphite filled conductive adhesive. Synth. Met. 159, 619-624 (2009)

11. M. Heimann, J. Lemm, K.-J. Wolter, Experimental investigation of carbon nanotubes/epoxy composites for electronic applications, in Proc. XXXI international conference of IMAPS Poland chapter, Rzeszów-Krasiczyn, 2007, pp. 55-61

12. J. Inoue, L. Masahiro, Electrical and thermal properties of electrically conductive adhesives using a heat-resistant epoxy binder, in Proceedings of electronics system-integration technology conference (ESTC), 2008, pp. 1147-1152

13. D. Ren, M. Mills, M. DeGroot, L. Clark, S. Brown, J. Curphy, Glass transition temperature as an in situ cure index of electrically conductive adhesives in solar photovoltaic module interconnect assemblies. Solar Energy Solar Cells 107, 403-406 (2012)

14. H. Li, C.P. Wong, A reworkable epoxy resin for isotropically conductive adhesives. IEEE Trans. Adv. Pack. 27(1), 165-172 (2004)

15. R.J.C. Carbas, E.A. Marquez, L.F.M. da Silva, A.M. Lopes, Effect of cure temperature on the glass transition temperature and mechanical properties of epoxy adhesives. J. Adhes. 19(1), 104-119 (2014)

16. A. Borisova, T. Glaskova-Kuzmina, A. Aniskevich, Thermophysical and mechanical properties of bisphenol a epoxy resin filled with multiwalled carbon nanotubes. Lith. J. Phys. 55(3), 191-199 (2015)

17. M. Urbaniak, A relationship between the glass transition temperature and the conversion degree in the curing reaction of the EPY epoxy system. Polimery 56(3), 240-243 (2011)

18. J. Foreman, S.R. Sauerbrunn, C.L. Marcozzi, Exploring the sensitivity of thermal analysis techniques to the glass transition, in TA instruments, applications library search, 2006, p. 14

19. R. Polansky, V. Mentlik, P. Prosr, J. Susir, Influence of thermal treatment on the glass transition temperature of thermosetting epoxy laminate. Polym. Testing 28, 428-436 (2009)

20. G.W. Ehrenstein, G. Riedel, P. Trawiel, Thermal analysis of plastics, theory and practice (Carl Hanser Verlag, GmbH \& Co. KG, Munich, 2004) pp. 236-299

21. X. Yang, Y. Guo, X. Luo, N. Zheng, T. Ma, J. Tan, C. Li, Q. Zhang, J. Gu, Self-healing, recoverable epoxy elastomers and their composites with desirable thermal conductivities by incorporating BN fillers via in-situ. Composit. Sci. Technol. 164, 59-64 (2018)

22. C. Liang, P. Song, H. Gu, C. Ma, Y. Guo, H. Zhang, X. Xu, Q. Zhang, J. Gu, Nanopolydopamine coupled fluorescent nanozinc oxide reinforced epoxy nanocomposites. Compos. A 102, 126136 (2017)

23. J. Gu, X. Yang, C. Li, K. Kou, Synthesis of cyanate ester microcapsules via solvent evaporation technique and its application in epoxy resins as a healing agent. Ind. Eng. Chem. Res. 55(41), 10941-10946 (2016)

24. Y. Huangfu, C. Liang, Y. Han, H. Qiu, P. Song, L. Wang, J. Kong, J. Gu, Fabrication and investigation on the $\mathrm{Fe}_{3} \mathrm{O}_{4}$ /thermally annealed graphene aerogel/epoxy electromagnetic interference shielding nanocomposites. Compos. Sci. Technol. 169, 70-75 (2019)

25. Y. Guo, G. Xu, X. Yang, K. Ruan, T. Ma, Q. Zhang, J. Gu, Y. $\mathrm{Wu}, \mathrm{H}$. Liu, Z. Guo, Significantly ehanced and precisely modeled thermal conductivity in polyimide nanocomposites with chemically modified graphene via in situ poloymerization and electrospinning-hot press technology. J. Mater. Chem. C 6(12), 30043015 (2018)

26. K. Ruan, Y. Guo, Y. Tang, Y. Zhang, J. Zhang, M. He, J. Kong, $\mathrm{J}$. Gu, Improved thermal condictivities in polystyrene nanocomposites by incorporating thermal reduced graphene oxide via electrospinning-hot press technique. Compos. Commun. 10, 68-72 (2018)

27. J. Gu, X. Yang, Z. Lv, N. Li, C. Liang, Q. Zhang, Functionalized graphite nanoplatelets/epoxy resin nanocomposites with high thermal conductivity. Int. J. Heat Mass Transf. 92, 15-22 (2016)

28. J.E. Morris, J. Liu, Electrically conductive adhesives: a research status review. micro- and opto-electronic materials and structures: physics, mechanics, design, reliability, packaging (Springer, Berlin, 2007) pp. B527-B570. http://www.tainstruments.com/wpcontent/uploads/TMA.pdf. Accessed 2 May 2018.

29. J.A. Dudek, J.A. Kargol, Linear thermal expansion coefficients for an epoxy/glass matte-insulated solid transformer. Int. J. Thermophys. 9(2), 245-253 (1988)

30. K. Shirasu, G. Yamamoto, I. Tamaki, T. Ogasawa, Y. Shimamura, Y. Inoue, T. Hashida, Negative axial thermal expansion coefficient of carbon nanotubes: experimental, determination based on measurements of coefficient of thermal expansion for aligned carbon nanotube reinforced epoxy composites. Carbon 95, 904-909 (2015)

31. Ch Wei, D. Srivastava, K. Cho, Thermal expansion and diffusion coefficients of carbon nanotube-polymer composites. Nano Lett. 2(6), 647-650 (2002)

32. J. Liu, Z. Lai, Overview of conductive adhesive joining technology in electronics packaging applications, in Proceeding 3rd international conference on adhesive joining and coanting technology in electronics manufacturing, Binghamton, USA, 1998, pp. 1-17

33. M.R. Bowdich, The durability of ahesive joints in the presence of Water. Int. J. Adhes. Adhes. 16(2), 73-79 (1996)

34. K.A. Kasturiarachchi, G. Pritchard, Scanning electron microscopy of epoxy-glass laminates exposed to humid conditions. J. Mater. Sci. 20, 2038-2044 (1985)

35. K. Saarinen, L. Frisk, Changes in adhesion of non-conductive adhesive attachments during humidity test. IEEE Trans. Comp. Pack. Manuf. Technol. 1(7), 1082-1088 (2011)

36. N.G. Sahoo, S. Rana, J.W. Cho, L. Li, S.H. Chan, Polymer nanocomposites based on functionalized carbon nanotubes. Prog. Polym. Sci. 35, 837-867 (2010)

37. U. Vohrer, J. Holmes, Z. Li, A. Teh, P. Papakonstantinou, M. Ruether, W. Blau, Tailoring the wettability of carbon nanotube powders, bucky papers and vertically aligned nanofibers by plasma assisted functionalization. AZojomo: DESYGN IT-Special Edition. (2007). https://doi.org/10.2240/azojono0126

Publisher's Note Springer Nature remains neutral with regard to jurisdictional claims in published maps and institutional affiliations. 